\title{
A IDEIA DE RAZÃO PÚBLICA DE JOHN RAWLS E O RECONHECIMENTO JURÍDICO DA UNIÃO HOMOAFETIVA NO BRASIL
}

\section{Bruno Martins Soares ${ }^{1}$}

\section{Resumo}

Este artigo tem como principal objetivo avaliar, segundo os critérios da ideia de razão pública de John Rawls, a legitimidade da decisão do Supremo Tribunal Federal brasileiro sobre o reconhecimento da união homoafetiva. Para tanto, retomo sua ideia de razão pública e defendo que ela deve ser compreendida como um ideal a guiar a ação na realidade. Inicialmente, como suporte a sua concepção de razão pública, apresento o ideal rawlsiano de pessoa: um cidadão racional e razoável, dotado das capacidades morais de se ter uma concepção de bem e um senso de justiça, que age de forma reciprocamente respeitosa, membro de uma sociedade democrática, constitucional e bem-ordenada segundo princípios de justiça. Demonstro também como a razão pública deve orientar autoridades públicas no debate sobre questões políticas fundamentais, de forma a possibilitar a constituição de uma estrutura social básica tolerante. Finalmente, ao aplicar os critérios da razão pública à referida decisão do STF, concluo por sua legimitidade.

Palavras-chave: Liberalismo; John Rawls; Tolerância; Razão Pública; União Homoafetiva.

\section{INTRODUÇÃO}

Muito se discute se o liberalismo abarca ou não as demandas de movimentos sociais e grupos que clamam por ações do Estado no sentido de promover uma igualdade para além da meramente formal, e até mesmo da redistribuição de recursos; uma igualdade que lhes reconheça o que possuem de peculiar e lhes atribua um valor positivo por essa mesma peculiaridade. Mas liberalismos são vários. Basta uma breve mirada no debate mencionado e já se evidencia como os críticos dos liberais - incluem-se nesse rol, especialmente, os teóricos do comunitarismo, do multicultarismo e do reconhecimento - confundem conceitos e correntes a que os diversos teóricos liberais se filiam. Sendo assim, este texto centrar-se-á no papel da tolerância na elaboração teórica da justiça igualitária de John Rawls, por ser ele o maior expoente do liberalismo contemporâneo - por isso mesmo, alvo frequente dos referidos críticos - e por ter elaborado um liberalismo tão peculiar, caracterizado por Nagel (2003, p. 63) como a combinação de princípios de igualdade econômico-social do socialismo europeu e de

\footnotetext{
${ }^{1}$ Coordenador Geral do Núcleo de Atendimento a Vítimas de Crimes Violentos. Mestre em Direitos Humanos pela Universidade de São Paulo. E-mail: brunommss@gmail.com
} 
liberdade e tolerância típicos do liberalismo americano, atribuindo a ambos um mesmo fundamento. ${ }^{2}$

Um argumento que orientará este texto é o de que Rawls contrói uma teoria ideal de justiça, ao propor princípios de justiça que surgiriam em circunstâncias idealizadas e operariam em uma sociedade também idealizada, como a sociedade bem-ordenada, na qual se presume que todos seus membros sejam justos comportam-se conforme os princípios de justiça - e estejam motivados a sustentar instituições justas (RAWLS, 2008, p. 10). Não obstante, a teoria ideal de justiça igualitária de Rawls tem o objetivo maior de "guiar a ação em circunstâncias não-ideais", e o fato de ser ideal é exatamente aquilo que a permite fazê-lo, pois "uma teoria de justiça deveria ser guia da ação no sentido de oferecer uma estrutura de pensamento desde a qual se possa avaliar, criticar e reformar a maneira como o poder é exercido na sociedade" (VALENTINI, 2009, p. 337, tradução nossa).

Atendo-me à dimensão ideal da teoria de justiça rawlsiana, proponho neste texto avaliar o julgamento da Ação de Descumprimento de Preceito Fundamental no 132 (APDF 132) e da Ação Direta de Inconstitucionalidade ${ }^{\circ} 4277$ (ADI 4277), ambas requerendo o reconhecimento jurídico da união estável entre homossexuais, a chamada união homoafetiva. Já se sabe que o Supremo Tribunal Federal brasileiro (BRASIL) deu procedência a esse pedido. Contudo, pergunto: a decisão do STF é legítima, segundo os critérios da razão pública de Rawls? Para responder essa pergunta, por meio de uma análise qualitativa de trechos do acórdão, desejo averiguar se e em que medida os Ministros do STF orientaram-se pelo discurso liberal rawlsiano, especialmente por sua ideia de razão pública ao aprovarem por unanimidade o pedido de reconhecimento da união homoafetiva. A partir dessa análise, pretendo demonstrar que a ideia de razão pública elaborada por Rawls é um conceito aberto, inclusivo, capaz de abranger e respeitar as mais diversas formas de vida e de, por essa razão, atender às demandas razoáveis dos movimentos sociais contemporâneos.

A análise proposta será realizada na quarta seção do texto. Na segunda seção, para introduzir as bases teóricas da razão pública, apresento uma sistematização do conceito de pessoa construído por Rawls e suas principais características, como as faculdades de racionalidade e de razoabilidade, as capacidades morais de se ter uma concepção de bem e um senso de justiça, a disposição de propor e aceitar termos equitativos de cooperação social e de reconhecer os limites do juízo e outros aspectos que compõem o cidadão rawlsiano. Dessa maneira, concluo que o cidadão de Rawls é capaz de exercitar a alteridade, de reconhecer o outro como sujeito de mesmo status e, por isso, merecedor de igual respeito. Além disso, esse não é um conceito fechado, estático de cidadão, mas sim uma ideia de pessoa a ser contextualizada, seja enquanto membro de um determinado grupo, comunidade, ou enquanto portador de uma determinada doutrina abrangente.

Na seção seguinte, apresento como, a partir de sua concepção de cidadão de uma sociedade democrática

\footnotetext{
${ }^{2}$ No mesmo sentido, Vita (2009, p. 65) aponta como fundamento comum à tolerância e à justiça distributiva a ideia normativa de sociedade democrática formulada por Rawls. Ao longo deste texto, a ideia de sociedade democrática será apresentada.
} vol.09, nº. 01, Rio de Janeiro, 2016.pp. 222-243 
constitucional bem-ordenada, Rawls constrói sua ideia de razão pública, que funciona como o aparato de argumentação e justificação a ser idealmente adotado por autoridades públicas e cidadãos em um debate público, quando estejam em discussão elementos constitucionais essenciais e questões de justiça básica. Serão apresentadas também interpretações e formulações da razão pública rawlsiana realizadas por Nagel, Scanlon e Barry, para se concluir que ela representa uma forma imparcial de justiça, por conceber a estrutura básica da sociedade de maneira tal que não priorize nenhuma concepção de bem ou forma de vida sobre as outras. Portanto, assim como a concepção de pessoa de Rawls, sua ideia de razão pública é aberta, apta a ser preenchida por qualquer concepção política de justiça que seja razoável.

\section{O CIDADÃO IDEALIZADO}

Rawls introduz a questão da tolerância em sua teoria em um segundo momento, após a definição dos princípios de justiça a ordenarem a estrutura básica da sociedade, formulando-a como uma questão sobre a estabilidade de uma sociedade justa na qual cidadãos livres e iguais professam livremente doutrinas morais razoáveis sobre o bem, sejam elas de natureza religiosa, filosófica ou outra, configurando-se assim o fato do pluralismo razoável, "produto inevitável das faculdades da razão humana quando exercidas sob uma estrutura duradoura de instituições livres" (RAWLS, 2011, p. 56).

De imediato, o problema assim formulado chama a atenção pelo fato de Rawls se propor trabalhar com uma ideia de sociedade na qual os princípios de justiça estão colocados em prática, e na qual os cidadãos já conhecem suas posições na sociedade e se orientam por concepções daquilo que entendem como o bem, diferentemente da situação da tão criticada (muitas vezes, por ser mal compreendida) posição original e seu véu de ignorância ${ }^{3}$. Rawls concebeu os princípios de justiça igualitária e sua ordem lexical (a prioridade do primeiro princípio de justiça, o de liberdade igual, em relação ao segundo, que inclui os princípios de igual oportunidade e o de diferença) numa situação ideal, a da posição original, de maneira que definissem um sistema perfeitamente justo e que se aplicasse a uma sociedade perfeitamente justa, democrática, isto é, a uma sociedade na qual os cidadãos estão plenamente cientes dos princípios da justiça igualitária definidos na posição original e se comportam conforme os mesmos (RAWLS, 2008, p. 301-304). Mas também reconheceu que o "modo como a justiça exige que enfrentemos a injustiça constitui um problema bem diferente do melhor modo de lidar com as inevitáveis limitações e contingências da vida humana" (RAWLS, 2008, p. 304). Tais inevitáveis limitaçôes e contingências da vida humana, como já apresentado, são identificadas por Rawls como o fato do pluralismo moral

\footnotetext{
${ }^{3}$ Para uma discussão de como o argumento da posição original deve ser melhor compreendido, ver VITA, 2007, p. 183-192. Nesse trecho, Vita apresenta que o que há de peculiar ao contratualismo de Rawls em relação aos contratualistas que o antecederam é, especialmente, o fato de ele ser construído desde uma perspectiva de imparcialidade moral, na qual as pessoas não agem de forma puramente racional, mas também agem motivadas por um senso de justiça. É justamente essa imparcialidade moral associada à capacidade moral de se ter um senso de justiça que Rawls tenta representar em sua posição original.
} vol.09, nº. 01, Rio de Janeiro, 2016.pp. 222-243 
razoável, resultante de duas capacidades distintas e complementares do cidadão: a de se ter um senso de justiça e a de se ter uma concepção de bem. Assim, nesse segundo momento de sua teorização, Rawls continua a trabalhar em circunstâncias ideais, mas completamente diferentes daquelas expostas na posição original, na qual, como consequência do véu de ignorância, as partes não podem levar em consideração as doutrinas do bem professadas pelos cidadãos que representam. É imperativo, então, apresentar os termos em que Rawls constrói esse novo cidadão, para uma adequada compreensão do problema da (in) tolerância e de sua proposta de resolução, que se configura na ideia de razão pública, a ser explanada mais adiante, na terceira seção.

Ainda, em concordância com o trabalho que se pretende realizar aqui de apresentar a teoria da justiça de Rawls enquanto ideal capaz de guiar a ação de pessoas e instituições reais, é igualmente importante compreender desde já que, como observado por Valentini (2009, p. 353), a existência concreta dessa pessoa não é condição necessária para a aplicação dos princípios de justiça. Dizer o contrário tornaria a construção teórica de Rawls irrelevante quando aplicada às circunstâncias reais. Compreendida adequadamente, a concepção de pessoa em Rawls funciona não como parte inerente aos princípios de justiça, mas sim como um suporte de justificação de tais princípios, como parte das circunstâncias nas quais os princípios são concebidos. Sendo assim, o que o ideal de cidadão rawlsiano e suas outras idealizações

Articulam são as circunstâncias sob as quais parece plausível construir uma teoria de justiça, não os sujeitos ou agentes aos quais uma teoria de justiça deve ser aplicada. [...] tais idealizações não são parte dos princípios de Rawls [...], são meramente parte dos argumentos que os apóiam. [...] o apelo a predicados ideais no desenho de uma teoria de justiça não resulta inevitavelmente em conclusões práticas infundadas, ao menos não enquanto tais predicados não sejam tomados como condição para a aplicabilidade da teoria. (VALENTINI, 2009, p. 353, grifo da autora, tradução nossa)

Observações preliminares realizadas, finalmente passo a tratar do ideal rawlsiano de cidadão. Sobre esse tema, uma das ideias fundamentais com que Rawls trabalha é o do racional. A pessoa é racional para além do mero cálculo meios-fins, pois possui concepções de bem que não necessariamente dizem respeito apenas à própria pessoa, mas podem fundar-se nos vínculos afetivos que ela possui com outras pessoas, comunidades e lugares, por exemplo, de modo que ajuste seus fins a tais concepções de bem. Consequentemente, os benefícios advindos dessa concepção de bem tampouco são meramente individuais, como sugeriria a simples adequação de meios a fins segundo um cáculo de eficiência e vantagem, mas são benefícios que podem referir-se a toda uma comunidade. Assim explicitado, o racional relaciona-se à capacidade do cidadão de possuir uma concepção de bem (RAWLS, 2011, p. 59-61).

Além de racional, uma pessoa pode também ser razoável. A razoabilidade é definida por Rawls segundo dois aspectos básicos, ambos fundados no chamado critério de reciprocidade. A razoabilidade se dá, portanto, numa relação intersubjetiva, em que um age sempre em relação ao outro, num exercício compreensivo de alteridade. Nesses termos, a reciprocidade evidencia-se na explicação oferecida por Rawls sobre os aspectos do razoável. O primeiro deles é o de que as pessoas estão dispostas a propor termos equitativos de cooperação social, 
os quais todos estejam também dispostos a cumprir e nos quais as pessoas encontrem motivação para agir, por serem termos razoáveis. Dessa forma, ao ingressar no debate público, uma pessoa reconhece limitações à aceitabilidade - por outros - das ideias que propõe, isto é, reconhece que a aceitabilidade de sua concepção de bem encontra um limite que se define na perspectiva do outro, na capacidade de o outro também realizar julgamentos e que, por esse motivo, todos devem se dispor a propor e a aceitar termos de cooperação social que sejam razoáveis a todos de maneira tal que possam servir de base motivacional à ação:

Se sustentamos que se deve negar a alguns a liberdade religiosa, é preciso que lhes ofereçamos razões que eles não apenas possam compreender - do mesmo modo que Serveto podia compreender porque Calvino queria queimá-lo na estaca -, mas razões que possamos razoavelmente esperar que eles também possam, como pessoas livres e iguais, razoavelmente aceitar. (RAWLS, 2011, p.LVI)

Desde que esse reconhecimento se dê de forma recíproca, a razoabilidade possibilita a criação de uma esfera pública de relações intersubjetivas de mútua confiança e mútuo respeito. Assim compreendido,

o razoável é público de uma forma que o racional não o é. Isto significa que é pelo razoável que entramos no mundo público de outros e nos dispomos a propor ou a aceitar, conforme o caso, termos equitativos de cooperação com eles. Estes termos, formulados como princípios, especificam as razões que devemos compartilhar e reconhecer publicamente uns perante os outros como a base de nossas relações sociais. Se formos razoáveis, nos disporemos a instituir aquela estrutura para o mundo social público que é razoável esperar que todos possam endossar e ajam em conformidade com ela, desde que se possa confiar em que os outros farão o mesmo. Se não pudermos confiar neles, será irracional, ou uma forma de autossacrifício, agir com base nesses princípios. (RAWLS, 2011, p. 63-64)

Enquanto o racional permite à pessoa desenvolver a capacidade moral de possuir uma concepção de bem, o razoável possibilita a formação da capacidade de se possuir um senso de justiça, como demonstra o segundo aspecto da razoabilidade, explanado a seguir.

A partir do primeiro aspecto da razoabilidade, Rawls encontra o fato do desacordo razoável entre pessoas razoáveis, e constata também a existência da fontes do desacordo, ou os limites do juízo (burdens of judgement), que se constituem nas "muitas contingências que fazem parte do exercício correto (e consciencioso) de nossas faculdades de razão e juízo no curso normal da vida política" (RAWLS, 2011, p. 66). Rawls exclui dessa definição os limites desarrazoados, como preconceitos e interesses meramente individuais, pois eles impediriam o estabelecimento de um acordo. Dessas observações, ele conclui que, na arena pública, os limites razoáveis do juízo levam pessoas razoáveis a diferentes conclusões sobre uma determinada controvérsia, limitando aquilo que pode ser justificado perante outros. O segundo aspecto do razoável é então entendido por Rawls (2011, p. 65) como a disposição de reconhecer limites ao julgamento e de aceitar que tal fato gera consequências ao uso da razão pública para a atribuição de justificação legítima ao exercício do poder político numa democracia constitucional.

Ao pensar o fato dos limites razoáveis do juízo para a compreensão de uma ideia de tolerância numa _vol.09, nº. 01, Rio de Janeiro, 2016.pp. 222-243 
democracia constitucional, Rawls (2011, p. 70-73) elabora uma definição de doutrina abrangente razoável enquanto uma doutrina de natureza moral (religiosa, filosófica ou outra), que se refira a aspectos fundamentais da vida humana, atribuindo maior relevância a determinados valores em detrimento de outros. Ele ainda lhe reconhece historicidade, o que permite conceber as doutrinas mutáveis ao longo do tempo. A razoabilidade da doutrina decorre justamente dos limites do juízo reconhecidos pelos cidadãos em uma democracia constitucional: os cidadãos reconhecem que sua doutrina é apenas uma entre várias; que, embora ela seja verdadeira desde sua perspectiva, ela pode não o ser desde a perspectiva do outro; e mais, que o outro pode possuir doutrinas que, para ele, sejam verdadeiras. Novamente, esse reconhecimento deve ser recíproco, para que seja razoável a todos. Consequentemente, cidadãos razoáveis vêem-se como portadores de liberdade igual (RAWLS, 2008, p. 263-264) e, por isso, entendem que seria desarrazoado utilizar a força coercitiva da sociedade para impor sua doutrina abrangente e reprimir as demais. Por outro lado, doutrinas abrangentes são desarrazoadas quando se colocam como verdadeiras em detrimento das demais, e seus fiéis são igualmente desarrazoados ao se comportarem de forma a tentar impô-las por meio do poder político. Tais considerações geram duas consequências importantes à formação de uma ideia de tolerância:

1. Um acordo baseado em uma doutrina abrangente seria impossível;

2. Cidadãos razoáveis só podem acordar em assegurar a todos alguma medida de liberdade de consciência.

Embora tolerância e liberdade de consciência sejam valores que trazem consigo uma carga moral - o que, a primeira vista, pareceria contraditório com a possibilidade mesma de um consenso -, ambos derivam de um liberalismo enquanto concepção política de justiça, não enquanto doutrina moral abrangente. Ao diferenciar concepções políticas de doutrinas morais, Rawls identifica três características das primeiras:

Primeiro, seus princípios aplicam-se às instituições políticas e sociais básicas (a estrutura básica da sociedade).

Segundo, podem ser formuladas de maneira independente de doutrinas abrangentes de qualquer tipo (embora possam, naturalmente, ser sustentadas por um consenso sobreposto razoável de tais doutrinas).

Finalmente, podem ser elaboradas a partir de ideias fundamentais, vistas como implícitas na cultura política pública de um regime constitucional, tais como as concepções dos cidadãos como pessoas livres e iguais e da sociedade como um sistema equitativo de cooperação. (RAWLS, 2011, p. 537)

Considerando essas características, ao tempo em que uma doutrina moral estabelece um modo de vida e de pensamento a seus fiéis ao se colocar como a verdade última, uma concepção política de justiça é aquela cujos princípios se aplicam apenas à estrutura básica da sociedade, que se legitima pelo critério de reciprocidade, independe de doutrinas abrangentes para se justificar, mas que tampouco as contradiz. A concepção política de justiça deve ser invocada por aqueles que sustentam essas mesmas doutrinas abrangentes quando desejarem 
apresentar justificação pública de propostas que nelas se baseiam, exigência denominada cláusula (RAWLS, 2011,p. 538).

É justamente no sentido político que Rawls atribui autonomia plena ao cidadão livre e igual da sociedade bem-ordenada: trata-se de autonomia política, restrita à vida pública dos cidadãos, quando participam de questões públicas da sociedade e usufruem dos direitos e liberdades garantidos pelos princípios de justiça. Por outro lado, quanto à autonomia ética - que abrange a vida social e individual da pessoa -, cabe ao próprio cidadão decidir se a aceita ou não, segundo sua própria doutrina abrangente (RAWLS, 2011, p. 92-93). Mas como se pode esperar que um cidadão tenha condições de realizar tal diferenciação? Pela regulação de seus desejos, mecanismo que possibilita a formação de uma psicologia moral razoável (RAWLS, 2011, p. 102-103) nos cidadãos. Rawls reconhece que, numa sociedade bem-ordenada, à qual se ingressa pelo nascimento e se deixa apenas pela morte, os princípios de justiça exercem uma função educativa (RAWLS, 2011, p. 85) em seus cidadãos. O cidadão que ali nasce é formado por tais princípios, dispondo-se a agir conforme esses princípios. Rawls (2008, p. 708) entende, então, que o cidadão possui o desejo de agir com base nos princípios de justiça, atribuindo-lhes máxima prioridade. Sendo assim, esse primeiro desejo torna-se regulador dos demais desejos e, portanto, estabelece limites à escolha que os cidadãos farão dos objetivos que realizarão e que formarão sua concepção de bem, ou sua doutrina abrangente razoável. Novamente enfatizando a ideia de reciprocidade, Rawls afirma que os cidadãos educados segundo os princípios de justiça têm o desejo de ser membros normais e cooperativos da sociedade e assim querem ser reconhecidos. Por meio desse aparato teórico, Rawls demonstra que o cidadão da sociedade bem-ordenada pelos princípios de justiça possui uma psicologia moral razoável, que the permite compreender como racional e razoável adotar a concepção política de justiça como reguladora última de seu plano de vida, diferenciando os sentidos político e ético da autonomia.

Concluindo esta seção, tem-se que a pessoa, ou cidadão rawlsiano é constituído das seguintes sete características:

1. As capacidades morais de possuir uma concepção de bem e de se ter um senso de justiça, ligadas às ideias do racional e do razoável, respectivamente;

2. A possibilidade de realizar julgamentos, destacando-se os de natureza moral;

3. O relacionar-se intersubjetivamente de forma recíproca, exercitando a alteridade;

4. A disposição de propor termos equitativos de cooperação social que sejam razoáveis a todos e o desejo de a eles se sujeitar, uma vez que haja expectativa legítima de que os outros também a eles se submeterão;

5. O reconhecimento de limites do juízo, que leva o cidadão a professar apenas doutrinas abrangentes e razoáveis e a

\footnotetext{
${ }^{4}$ Em outras palavras, a cláusula refere-se às condições em que justificações derivadas de doutrinas abrangentes razoáveis podem ser introduzidas em discussões públicas no fórum político público, sendo tais condições:

1. Basear-se em uma concepção política de justiça e

2. Estar em acordo com as exigências da razão pública.
} 
aceitar a existência e as consequências do desacordo razoável;

6. O desejo de se portar como membro plenamente cooperativo da sociedade e de assim ser reconhecido;

7. A psicologia moral razoável.

Nesses termos, tem-se que Rawls elabora uma concepção aberta de pessoa, por ser apenas política e não ética. Ele reconhece nas pessoas uma medida mínima de igualdade moral que as torne cidadãs de uma democracia constitucional, deixando abertas as mais diversas possibilidades de escolhas de como se portar, colocando como exigência apenas o respeito mútuo, assegurado pela aceitação de uma concepção política de justiça. Dentro desse único limite, a pessoa de Rawls pode se desenvolver da maneira que considerar melhor, da maneira que melhor contribuir à sociedade, assumindo a identidade que the aprouver. Por essa razão, não há de se falar em uma ideia essencialista, normalizadora de pessoa, mas histórica, contextual.

Tendo em vista que esse texto tem como um de seus propósitos avaliar uma forma específica de o Estado lidar com seus cidadãos (no caso, o STF brasileiro e sua decisão sobre a união homoafetiva), depois de compreendido o ideal rawlsiano de pessoa como cidadã racional e razoável, é necessário também entender como devem orientar-se as relações por ela estabelecidas com a estrutura básica e com os demais cidadãos. Para Rawls, esse relacionamento deve guiar-se por uma ideia de razão pública, construída e sustentada a partir de seu ideal de cidadão.

\section{IDEIA E IDEAL DE RAZÃO PÚBLICA}

Da seção anterior, depreende-se que Rawls constrói uma teoria ideal de justiça, trazendo uma concepção de sociedade democrática bem-ordenada, isto é, uma sociedade regida por uma democracia constitucional, na qual os princípios de uma concepção política de justiça (no caso de Rawls, de justiça igualitária) sejam o fundamento da estrutura básica, que seja composta por cidadãos livres e iguais que se orientam por tais princípios e que, por ser assim organizada, haja pluralismo de doutrinas abrangentes razoáveis, ainda que irreconciliáveis. Depreende-se, ainda, que o cidadão membro de uma tal sociedade é idealmente constituído das seguintes características:

1. Além da capacidade de ter uma concepção do bem, os cidadãos têm a capacidade de adquirir concepções de justiça e equidade e de agir em conformidade com essas concepções;

2. Quando acreditam que as instituições ou práticas sociais são justas ou equitativas (como essas concepções especificam), os cidadãos se mostram prontos e dispostos a fazer sua parte nesses arranjos, desde que tenham garantias razoáveis de que os demais farão o mesmo;

3. Se outras pessoas, com uma intenção manifesta, se empenham em fazer sua parte em arranjos justos ou equitativos, os cidadãos tendem a aumentar a confiança que neles depositam; 
4. Essa confiança se torna mais forte e completa conforme o sucesso dos arranjos cooperativos se estende por períodos mais longos de tempo; e

5. O mesmo se pode dizer quando as instituições básicas estabelecidas para garantir nossos interesses fundamentais (os direitos e liberdades básicos) se tornam mais firme e voluntariamente aceitas. (RAWLS, 2011, p. 103)

Portanto, ao levar em conta o fato do pluralismo de doutrinas abrangentes razoáveis em uma democracia constitucional formada por cidadãos racionais e razoáveis possuidores de todas as características anteriormente apresentadas - destacadamente, o agir recíproco -, Rawls (2011, p. 74-77) constata que a base da unidade social - isto é, aquilo que proporciona a estabilidade de uma sociedade - não é um acordo sobre uma determinada doutrina abrangente, mas sobre uma concepção política de justiça, tal qual o princípio de tolerância. Estabelece-se esse acordo por meio do que Rawls (2011, Conferência IV) chama de consenso sobreposto de doutrinas abrangentes e razoáveis: as próprias doutrinas, ainda que irreconciliáveis, quando razoáveis, legitimam a concepção política desde dentro, isto é, a partir de e segundo os pontos de vista que lhes são peculiares. É acordo que se constitui num equilíbrio racional e razoável efetuado por cada cidadão entre concepção política e seus planos de vida, sendo que esse equilíbrio é base do respeito aos limites impostos pelo que Rawls denomina ideia de razão pública, pois, como se demonstrará a seguir, é justamente o respeito a esses limites que garante a permanência de uma concepção política de justiça, assegurando também a possibilidade de reconhecimento de direitos a homossexuais os quais já tenham sido reconhecidos a heterossexuais. Dito de outra forma, uma concepção política de justiça que forneça o conteúdo da razão pública deve ser uma "visão que se sustenta por si própria" (RAWLS, 2011, p. 12, passim). Os conceitos de critério de reciprocidade, de concepção política de justiça, de concepção política de pessoa e de razão pública são mobilizados por Rawls nessa visão ou justificação que se sustenta por si, isto é, que não se fundamenta em nenhuma doutrina moral abrangente, seja ela razoável ou não. A introdução da ideia de razão pública nessa justificação enquanto caracterizadora da relação política dos cidadãos possibilita à concepção política de justiça ser objeto de um consenso sobreposto de doutrinas razoáveis.

A ideia de razão pública traz em si os valores morais e políticos que devem conduzir a relação de um governo democrático com seus cidadãos, bem como as relações dos cidadãos entre si. Em razão do fato do pluralismo razoável, a razão pública trabalha com o politicamente razoável, não com o verdadeiro, ou com o bem último. Por isso, ela não deve contrariar nenhuma doutrina abrangente ou concepção de bem que seja razoável. As relações ordenadas pela razão pública fundamentam-se, portanto, no já conhecido critério de reciprocidade.

Rawls define a ideia de razão pública como possuidora de três características, que a tornam pública: é razão adotada por cidadãos livres e iguais; tem como objeto o bem público, isto é, as matérias de justiça política fundamental, quais sejam, elementos constitucionais essenciais e questões de justiça básica; sua natureza e conteúdo são publicamente divulgados, reciprocamente partilhados e expressos no debate público por meio de 
concepções políticas de justiça que sejam razoáveis, satisfazendo o critério de reciprocidade (RAWLS, 2011, p. 524-525). Ademais, a ideia de razão pública não se aplica a qualquer discussão pública. Pelo contrário, possui um âmbito de atuação bastante restrito, mas fundamental para garantir a estabilidade de uma sociedade democrática constitucional bem-ordenada. Para esse ponto, deve-se entender que Rawls trabalha com uma noção de democracia deliberativa, na qual cidadãos ingressam na arena pública dispostos a apresentar argumentos para defender determinadas políticas públicas, bem como a compreender e aceitar discursos que apresentem argumentos razoáveis, ainda que contrários a sua defesa: "[e]les [os cidadãos] supõem que suas opiniões políticas podem ser revistas por meio da discussão com outros cidadãos e não são, portanto, simplesmente um produto rígido de seus interesses privados ou não políticos" (RAWLS, 2011, p. 531). Obviamente, trata-se de um ideal de democracia deliberativa, que possui, fundamentalmente, três elementos: a própria ideia de razão pública; uma estrutura constitucional democrática que defina as instituições legislativas deliberativas; a plena ciência e desejo dos cidadãos de agir conforme a ideia de razão pública e de que ela se concretize na conduta política da sociedade.

Outro ponto importante é que a ideia de razão pública se aplica às discussões ocorridas no que Rawls chama de fórum político público (RAWLS, 2011, p. 525), compreendendo três grupos de discursos públicos: o presente em decisões judiciais, especialmente as emitidas por tribunais constitucionais; o de autoridades públicas, como os dirigentes dos Poderes Executivo e Legislativo; e o dos candidatos a cargos públicos, em especial, o discurso que é publicamente proferido em campanhas, declarações e programas partidários. Por outro lado, a ideia de razão pública não se aplica ao que Rawls denomina cultura de fundo (RAWLS, 2011, p. 526), ou cultura da sociedade civil, na qual os cidadãos se associam e debatem livremente, sendo que tais debates podem ocorrer com base nas mais diversas razões não-públicas.

O objeto da ideia de razão pública é o que Rawls chama de questôes políticas fundamentais, que se apresentam em duas formas: os elementos constitucionais essenciais, que abrangem aqueles direitos e liberdades que podem fazer parte de uma Constituição - considerando que ela poderá ser interpretada por um tribunal constitucional -, tais como "os direitos civis, os direitos e as prerrogativas associados à noção de Estado de Direito e os direitos e as liberdades associados a uma estrutura democrática de autoridade política” (VITA, 2009, p. 70); e as questões de justiça básica, concernentes à justiça distributiva, as quais, por sua vez, possuem apenas um núcleo mínimo que deve constar de uma Constituição ${ }^{5}$. Dessa forma, Rawls não entende a razão pública como mero

Teste mecânico para avaliar a admissibilidade de argumentos, mas sim como a caracterização daquilo que deveríamos buscar em um terreno admissível para o desenho de instituições básicas. [... o senso de justiça deveria nos levar a tentar, de boa fé, oferecer aos nossos concidadãos motivos para o exercício do poder coletivo que acreditemos que eles, desde seu ponto de

\footnotetext{
${ }^{5}$ Sobre esse assunto, Michelman (2008, p. 404-407) entende que, para Rawls, necessidades materiais básicas, junto das liberdades políticas, são recursos a serem abrangidos no conceito de elementos constitucionais essenciais. O que pode provocar dúvida no texto de Rawls é quanto a se o excedente a esse núcleo mínimo (como o princípio de diferença, por exemplo) deve ser constitucionalizado. Se, suponhamos, o princípio de diferença for constitucionalizado, Rawls entende que tal ato incorrerá num problema de transparência, pois cidadãos racionais e razoáveis nunca saberão julgar devidamente se ele está sendo cumprido.
} vol.09, nº. 01, Rio de Janeiro, 2016.pp. 222-243 
vista enquanto companheiros argumentadores [fellow reasoners], tenham razão para aceitar - ainda que, de fato, eles não aceitem. (NAGEL, 2003, p. 76, tradução nossa)

Como bem formulado por Nagel, mais do que simplesmente avaliar argumentos, a razão pública tem a função primordial de prover instituições da estrutura básica que sejam razoavelmente aceitas a todos os membros de uma sociedade. Assim, da razão pública resulta uma forma específica de tolerância fundamentada no respeito mútuo e que se expressa pela imparcialidade quando se lida com questões políticas fundamentais. Essa interpretação da razão pública encontra formulação bastante fiel a Rawls nas sistematizações realizadas não apenas por Nagel, mas também por Barry e Scanlon, como exposto a seguir.

Rawls constrói uma estrutura para a razão pública que leva em consideração sua própria concepção de cidadão racional e razoável de uma democracia constitucional, especialmente as características:

1. Da disposição que o cidadão possui de propor e aceitar termos equitativos que a todos sejam razoáveis e a

2. Do reconhecimento dos limites do juízo, que limitam o campo de justificações a serem apresentadas na discussão pública.

Ao interpretar a razão pública rawlsiana associada a tais características do cidadão, Nagel entende que ela:

Não deve ser pensada como um procedimento decisório efetivo, que garantidamente produzirá acordo, mas sim como uma forma especial de desacordo, argumento e contra-argumento, que tenta utilizar métodos de avaliação e prova mutuamente reconhecidos, quer produzam consenso ou não. (NAGEL, 2003, p. 76, tradução nossa)

Portanto, para serem razoáveis - ou seja, mutuamente reconhecíveis, inteligíveis -, os termos e argumentos apresentados por um cidadão não devem se basear unicamente em sua doutrina abrangente, ou suas concepções privadas. Como se vê, Rawls retira do campo de abrangência da razão pública argumentos e meios de prova e avaliação que sejam tão controversos - tais como aqueles que envolvam questões morais muito profundas, como as de natureza religiosa - que não se chegaria a um acordo. ${ }^{6}$ Nesse mesmo sentido, Barry apresenta sua concepção de justiça como imparcialidade, que muito se aproxima da ideia de razão pública rawlsiana. Um dos principais argumentos da justiça como imparcialidade - assim como o da ideia de razão pública - reside na atribuição de simetria de status às concepções de bem. Disso decorre que não há um único fim, ou bem a ser adotado como base de instituições sociais e tornado vinculante a todos os membros de uma sociedade, mas, ao contrário, as demandas efetuadas no debate público devem ser dotadas de razoabilidade

\footnotetext{
${ }^{6}$ Sobre esse tema, vale mencionar a observação de Nagel ao dizer que "invocar apenas nossas convicções privadas é, de acordo com Rawls, uma violação do requerimento de reciprocidade que se aplica a membros de uma sociedade justa” (NAGEL, 2003, p. 76, grifo nosso, tradução nossa). Destaco que a interpretação aqui adotada em nada se aproxima de uma negação de legitimidade a qualquer argumento que, em alguma medida, esteja baseado em questões morais referentes a alguma doutrina abrangente, posicionamento tão criticado por Scanlon (2003, p. 190-192). Trata-se apenas de realizar uma distinção entre argumentos públicos, potencialmente inteligíveis, reconhecíveis e aceitáveis a outros, e argumentos meramente privados, por serem baseados unicamente em convicções que apenas seu emissor possui - e, eventualmente, alguns outros membros da sociedade partilham, mas não todos - e pode compreender. Na verdade, é perfeitamente possível e legítimo que, em uma discussão pública, seja colocado um argumento que se fundamente em um determinado posicionamento religioso, por exemplo, mas que, apresentando razões publicamente partilhadas, seja razoável a todos, cumprindo com as exigências da razão pública, satisfazendo a já mencionada cláusula.
} 
(BARRY, 1995, p. 82, 142). Para sustentar sua posição, Barry utiliza as condições de imparcialidade elaboradas por Scanlon, em especial a circunstância motivacional", segundo a qual cidadãos possuem uma "disposição de aceitar objeções razoáveis a uma proposta, seja lá de onde venham” (BARRY, 1995, p. 100, tradução nossa). É evidente, portanto, que Barry - em referência a Scanlon - apropria-se da ideia rawlsiana de cidadão razoável e racional, apenas reformulando a disposição de apresentar termos equitativos de cooperação e de reconhecer os limites do juízo para uma ideia de imparcialidade enquanto disposição de propor e aceitar termos de cooperação que não possam ser razoavelmente rejeitados. ${ }^{8}$

Portanto, a razão pública de Rawls e a justiça como imparcialidade de Barry concebem a justiça como uma questão de imparcialidade de justificação quando da discussão de questões políticas fundamentais (BARRY, 1995, p. 144). Não se trata de uma imparcialidade em relação aos resultados provenientes do processo deliberativo, mas sim de um processo deliberativo público cujas regras sejam imparciais, que tome todas as doutrinas abrangentes razoáveis como possuidoras de mesmo status, impossibilitando que uma se imponha sobre as outras por meio do poder político. A imparcialidade é apenas procedimental, pois um acordo possível num ambiente de pluralismo moral razoável só pode ser em relação a regras procedimentais, daí que a justiça resulta de um procedimento decisório justo:

Então, um procedimento decisório é justo na medida em que todos os envolvidos estejam bem informados e tenham seus interesses e perspectivas expressos com igual força e efetividade. Ele é justo na medida em que o que conta como um bom argumento não dependa da identidade social da pessoa que o elabora. Ele é justo, ainda, na medida em que, quando possível, almeje o consenso, mas quando não for possível, trate todos igualmente. (BARRY, 1995, p. 110, tradução nossa)

É dessa forma que Barry (1995, p. 113) propõe que a teoria da justiça como imparcialidade fornece uma estrutura sob a qual as pessoas podem viver, mas não impõe a forma como elas devem viver; e assim se apresenta sua concepção de tolerância. ${ }^{9}$ De forma similar, Rawls fixa uma estrutura para a ideia de razão pública, mas não chega a estabelecer-lhe um conteúdo - embora afirme que alguma concepção política de justiça deva especificarlhe um conteúdo -, ao qual corresponde uma determinada forma de interpretação, delimitando apenas que, qualquer que seja a concepção política de justiça que venha a preenchê-la, ela deve ser razoável, isto é, deve satisfazer o critério de reciprocidade, possibilitando aos cidadãos reconhecer que os valores políticos expressos pela concepção de justiça em questão sejam razoáveis a todos e passíveis de serem acatados. Rawls enumera uma

\footnotetext{
${ }^{7}$ Outra circunstância adotada por Barry é o do momento deliberativo, no qual argumentos são confrontados e avaliados, sendo que, desse momento, decorre a legitimidade da decisão (BARRY, 1995, p. 103).

${ }^{8}$ Essa aproximação fica ainda mais evidente quando Barry afirma que "termos razoáveis devem ser termos que não pressuponham a certeza de qualquer concepção de bem” (BARRY, 1995, p. 169, tradução nossa).

${ }^{9}$ De fato, Barry endossa a ideia rawlsiana de razão pública. Sua principal discordância com Rawls refere-se à ideia de um consenso sobreposto, a qual, para Barry (1995, p. 874-915), é desnecessária para a estabilidade da justiça como equidade.
} vol.09, nº. 01, Rio de Janeiro, 2016.pp. 222-243 
pequena lista de características que parecem ser comuns às concepções políticas de justiça que se apresentam em forma de razão pública:

Primeiro, uma lista de certos direitos, liberdades e oportunidades fundamentais (tais como os conhecidos de regimes constitucionais).

Segundo, uma atribuição de prioridade especial a esses direitos, liberdades e oportunidades, em especial no que diz respeito às exigências do bem geral e de valores perfeccionistas.

Terceiro, medidas que assegurem a todos os cidadãos os meios polivalentes adequados que thes possibilitem fazer uso efetivo de suas liberdades. (RAWLS, 2011, p. 534)

Rawls identifica um conteúdo mínimo comum a concepções de justiça derivadas da cultura pública de uma sociedade democrática e constitucional, mas deixa em aberto tanto a possibilidade de que diferentes concepções de justiça venham a preencher materialmente a razão pública, como também que os princípios de justiça, enquanto valores públicos ou políticos, sejam objeto de argumentação e interpretação racionais, razoáveis e públicas (MICHELMAN, 2008, p. 400). Rawls não fixa uma única forma de interpretação do conteúdo da razão pública justamente por compreender que ela deve ser contextualizada em relação a determinados grupos, em determinados local e período de tempo. Não cabe ao liberalismo político fixar-lhe uma única e estática interpretação e ignorar as contingências da vida humana, como o surgimento de novas necessidades e, por conseguinte, de novas demandas que devem ser discutidas em uma democracia constitucional.

Finalizando esta seção do texto, convém recordar que Rawls trabalha com uma teoria ideal de justiça e, consequentemente, em sua teoria, a ideia de razão pública também pode operar de forma ideal quando, numa deliberação pública sobre questões políticas fundamentais, é plenamente adotada por autoridades públicas e candidatos a cargos públicos ao justificarem seus argumentos com base na concepção política que considerarem mais razoável, agindo em cumprimento a seu dever de civilidade (um dever de natureza moral, correspondente ao respeito mútuo (VITA, 2009, p. 84)) em relação aos demais ocupantes de - ou candidatos a - cargos públicos e aos cidadãos (RAWLS, 2011, p. 526-528). Rawls reconhece também a possibilidade de os cidadãos cumprirem com seu dever de civilidade e realizarem o ideal de razão pública. Isso ocorre quando, ao se colocarem idealmente na posição de autoridades públicas ou candidatos a cargos públicos e imaginarem quais seriam os termos mais razoáveis - isto é, quais termos propostos não poderiam ser razoavelmente rejeitados segundo o critério de reciprocidade, ou de respeito mútuo -, os cidadãos controlam as autoridades públicas e fazem o que podem para que elas se mantenham fiéis à ideia de razão pública.

Esse é o ideal de razão pública apresentado por Rawls. Por ser ideal, não significa que ele seja utópico; o ideal não se opõe à realidade, mas se relaciona com ela, transformando-a. Como já mencionado, Rawls reconhece esse potencial transformador aos princípios da justiça igualitária e, claro, também à ideia de razão pública; 
potencial que se expressa em sua função educativa e, certamente, o sentido da educação apontado pela ideia de razão pública é o de tolerância, cujo valor reside no tipo de relação interpessoal que propicia, baseada no respeito mútuo, conforme apontado por Scanlon: "o que a tolerância expressa é o reconhecimento de uma condição comum de cidadania que é mais profundo que [...] conflitos, um reconhecimento de que os outros têm tanto direito quanto nós de contribuir para a definição de nossa sociedade" (SCANLON, 2003, p. 190, tradução nossa). Nos termos propostos por Rawls, a ideia de razão pública estimula o que Scanlon (2003, p. 198) chama de espírito da tolerância, como algo que nos leva a aceitar um determinado sistema de direitos que também seja aceitável aos demais, não como um sistema ideal, absoluto, mas que pode estar submetido a questionamentos e revisões, as quais são guiadas por esse mesmo espírito.

Baseado no ideal de razão pública rawlsiano e consciente de seu potencial transformador enquanto guia da ação, proponho uma breve análise de um momento da história brasileira recente, marcante por levantar o debate da garantia dos direitos civis no país: o reconhecimento do direito à união estável a casais homossexuais. Proponho avaliar se, na justificação da decisão proferida pelo STF no julgamento da ADI 4277 e da ADPF 132 em maio de 2011, os Ministros guiaram-se pelos critérios da ideia de razão pública e, portanto, se eles se aproximaram do ideal de razão pública como concebido por Rawls.

\section{RAZÃO PÚBLICA E UNIÃO HOMOAFETIVA}

Como observa Forst (2009, p. 15-16), a tolerância pode adquirir uma feição ambivalente quando arguida no debate público. Há casos em que o argumento da tolerância chega a ser usado tanto por um como pelo outro lado da discussão, de forma meramente conveniente, seja para defender seu argumento, seja para rejeitar o argumento do outro. Definir os limites da tolerância - isto é, até que ponto uma atitude é tolerante e onde começa a intolerância - é tarefa complexa, uma vez que tais limites não estão determinados a priori. Embora eles sejam indeterminados, são determináveis, sendo observáveis no caso concreto, segundo critérios previamente estabelecidos. Portanto, como bem diagnosticado por Scanlon (2003, p. 198), exatamente por serem indeterminados, questionar os limites da tolerância pode ser efetiva estratégia política a ser adotada, por exemplo, por movimentos sociais.

Nesta última seção, proponho analisar o julgamento de duas ações constitucionais submetidas ao Supremo Tribunal Federal brasileiro: a ADPF 132, proposta pelo Governo do Estado do Rio de Janeiro; e a ADI 4277, proposta pela Procuradoria Geral da República. ${ }^{10}$ Ambas as ações questionaram a interpretação que o

\footnotetext{
${ }^{10}$ Considerando que as duas ações coincidiram em seus objetos e pedidos, foram julgadas em conjunto pelo STF (BRASIL, 2011, p. 2077-2078).
} 
poder público vinha atribuindo aos dispositivos normativos constitucionais e infraconstitucionais sobre a união civil estável como direito restrito a casais heterossexuais. Também ambas tiveram como pedido principal o de que a tais normas fosse atribuída interpretação que reconhecesse em seu escopo os casais formados por pessoas do mesmo sexo, os casais homossexuais. Em outras palavras, os demandantes solicitaram ao STF que declare como intolerante a interpretação - até então - comumente realizada e que realize nova interpretação que trate igualmente heterossexuais e homossexuais. Trata-se, portanto, de uma evidente controvérsia sobre os limites da tolerância, que teve como resultado a procedência do pedido principal dos demandantes: o de reconhecimento da união civil estável como direito também de homossexuais. Mas tão ou, talvez, mais importante que a decisão em si, são as justificativas e argumentos apresentados de forma a sustentá-la, a atribuir-lhe legitimidade. Afinal, segundo os critérios da ideia de razão pública estabelecidos por Rawls, seria possível considerar legítima a decisão tomada pelo STF? Responderei essa pergunta ao longo desta seção.

Faço uma pequena observação quanto ao objeto de análise aqui proposto, isto é, o julgamento da ADPF 132 e da ADI 4277. Delimitarei meu estudo ao voto do Ministro Ayres Britto, relator das referidas ações constitucionais, uma vez que os outros nove ${ }^{11}$ Ministros presentes à sessão de julgamento unanimente votaram com o próprio relator. Dessa forma, pode-se presumir, razoavelmente, que todos os Ministros compartilham do discurso enunciado por Britto em seu voto, incluindo, por óbvio, as justificações ali apresentadas.

Inicio a análise pelo seguinte trecho:

É que ninguém ignora o dissenso que se abre em todo tempo e lugar sobre a liberdade da inclinação sexual das pessoas, por modo quase sempre temerário (o dissenso) para a estabilidade da vida coletiva. Dissenso a que não escapam magistrados singulares e membros de Tribunais Judiciários, com o sério risco da indevida mescla entre a dimensão exacerbadamente subjetiva de uns e de outros e a dimensão objetiva do Direito que lhes cabe aplicar.

[...]

Em suma, estamos a lidar com um tipo de dissenso judicial que reflete o fato histórico de que nada incomoda mais as pessoas do que a preferência sexual alheia, quando tal preferência já não corresponde ao padrão social da heterossexualidade. (BRASIL, 2011, p. 2077-2078, grifo do autor)

Já no início de seu voto, ao se ver confrontado com um argumento sobre a insegurança jurídica gerada pela falta de uniformidade de posicionamento nos julgamentos de processos administrativos e judiciais sobre o reconhecimento da união estável a casais homossexuais, podemos dizer que Britto compreende que os questionamentos trazidos pelo caso em questão dizem respeito a práticas e discursos intolerantes que se expressam não apenas na cultura de fundo ou na esfera privada dos cidadãos brasileiros, mas também na estrutura básica da sociedade, nomeadamente por juízes, quando em interpretação da Constituição (importante componente da estrutura social básica), deixam de assegurar direitos iguais (como de casamento, direitos sucessórios, previdenciários, de adoção e outros) em evidente atentado à razão pública e à estabilidade social.

\footnotetext{
${ }^{11}$ Observo que o Ministro Dias Toffoli se declarou impedido de julgar as ações, uma vez que, previamente a sua nomeação ao STF, já havia se manifestado sobre seu objeto (BRASIL, 2011, p. 2109). Ressalto que sua manifestação fora favorável ao reconhecimento da união homoafetiva.
} 
Britto reconhece a existência de uma pluralidade de comportamentos sexuais, fato que resulta em diferentes opiniões sobre os diferentes comportamentos. Reconhece também que, muitas vezes, a diversidade de opiniões resulta em risco à estabilidade da sociedade. Parece-me plausível afirmar que o Ministro não compreende a diversidade de opiniões como um risco em si, mas que o risco estaria na existência de posicionamentos intolerantes, como é bastante comum quando o assunto é diversidade sexual. Britto parece atribuir preocupação ainda maior a casos em que juízes fundamentam suas decisões em posicionamentos fortemente subjetivos, mas mascarados pela objetividade pretendida pelo Direito. Essa atitude do Ministro é bastante significativa, por representar uma sensibilidade moral que ele possui em relação a atitudes violatórias da razão pública.

Outro ponto essencial a ser compreendido no voto do Ministro é o objeto aos quais seus argumentos se dirigem e, principalmente, se esse objeto pode ser submetido à ideia de razão pública conforme elaborada por Rawls. No caso, o objeto de ambas as ações consitucionais é o mesmo, o da interpretação constitucional do art. 1.723 do Código Civil brasileiro de 2002, que enuncia o seguinte: "É reconhecida como entidade familiar a união estável entre o homem e a mulher, configurada na convivência pública, contínua e duradoura e estabelecida com o objetivo de constituição de família”. Em sua essência, o objeto do debate público nesse caso é a família e sua configuração. Mas pode a família figurar como questão política fundamental e, dessa forma, ser objeto da razão pública?

Rawls (2011, p. 554-563) reconhece que a família é parte da estrutura básica da sociedade e lhe atribui papel fundamental dentro de uma democracia constitucional, enquanto instituição formadora de cidadãos morais de uma democracia constitucional, como um espaço central onde se aplicam princípios de justiça - sobretudo, os direitos e liberdades fundamentais, os quais constituem-se em elementos constitucionais essenciais - e, portanto, é também local onde opera a distribuição de recursos. Nesse sentido, então, a família - e não toda a vida familiar é abrangida pelos princípios de justiça, ou por uma concepção política de justiça. Sendo assim, a controvérsias relacionadas à família - quando envolvem direitos, liberdades e oportunidades fundamentais de seus membros devem ser aplicados os critérios da razão pública rawlsiana. Dessa maneira se configura o caso sob análise.

Passando agora aos argumentos apresentados por Britto, destaco o seguinte trecho, no qual diz adotar em seu voto o termo homoafetividade:

[...] para identificar o vínculo de afeto e solidariedade entre os pares ou parceiros do mesmo sexo [ ... ]

Sucede que não foi somente a comunidade dos juristas, defensora dos direitos subjetivos de natureza homoafetiva, que popularizou o novo substantivo, porque sua utilização corriqueira já deita raízes nos dicionários da língua portuguesa, a exemplo do "Dicionário Aurélio". Verbete de que me valho no presente voto para dar conta, ora do enlace por amor, por afeto, por intenso carinho entre pessoas do mesmo sexo, ora da união erótica ou por atração física entre esses mesmos pares de seres humanos. [...]. Logo, vínculo de caráter privado, mas sem o viés do propósito empresarial, econômico, ou, por qualquer forma, patrimonial, pois não se trata de u’a $[$ sic $]$ mera sociedade de fato ou interesseira parceria mercantil. Trata-se, isto sim, de um voluntário navegar por um rio sem margens fixas e sem outra embocadura que não seja a experimentação de um novo a dois que se alonga tanto que se faz universal. E não compreender isso talvez comprometa por modo irremediável a própria capacidade de interpretar os institutos jurídicos [objetos da ação] há pouco invocados [...]. (BRASIL, 2011, p. 
2080-2081)

Britto inicia seu argumento ressaltando o significado da palavra homoafetividade, por denotar a capacidade das pessoas de construir relações afetivo-sexuais por outras pessoas do mesmo sexo. Ao adotar essa terminologia em seu voto, o Ministro parece tentar retirar do campo de discussão presunções que seriam desarrazoadas no debate público: a de que as relações entre pessoas do mesmo sexo seriam motivadas por desejos unicamente sexuais, resultando, portanto, em relações fundadas apenas no ato sexual; a de que o único tipo de comportamento sexual que estaria baseado no afeto não meramente sexual seria o comportamento heterossexual; e, consequência das anteriores, a de que homossexuais seriam incapazes de constituir uma família, já que desprovidos de capacidade afetiva.

Assim, Britto utiliza o recém-criado termo homoafetividade para se referir aos homossexuais, conferindo a essa forma de comportamento sexual o mesmo status que possui a heterossexualidade, à qual Britto ainda renomeou heteroafetividade (BRASIL, 2011, p. 2081), para igualar devidamente o tratamento na discussão. Para atribuir ainda mais legitimidade à utilização do termo homoafetividade, Britto se apóia no fato de que seu uso já foi amplamente difundido na sociedade brasileira, não se restringindo apenas ao vocabulário jurídico, mas já reconhecido por renomado dicionário brasileiro da língua portuguesa, sinal de sua popularização e aceitação.

Destaco ainda desse trecho o argumento segundo o qual a homoafetividade seria uma capacidade inerente e até mesmo universal ao ser humano. Ora, me parece que a pretensão de atribuir universalidade à homoafetividade pode ser razoavelmente questionada, pois é possível encontrar sociedades nas quais o comportamento homoafetivo não se manifesta. Além disso, Britto não apresentou meios de prova razoáveis para sustentar esse argumento. No entanto, a universalidade ou não dessa capacidade não prejudica a argumentação formulada pelo Ministro, pois não é requisito posto pela ideia de razão pública.

Faz parte da argumentação de Britto não apenas a constatação de igualdade entre heteroafetivos e homoafetivos, mas também a de tratamento não-discriminatório, ambos princípios que justificariam a "adoção de políticas públicas afirmativas da fundamental igualdade civil-moral (mais do que simplesmente econômicosocial) dos estratos sociais historicamente desfavorecidos e até vilipendiados"; políticas que, por sua vez, promoveriam "a plena aceitação e subseqüente experimentação do pluralismo sócio-políticocultural [sic]." (BRASIL, 2011, p. 2083, grifo do autor). É importante ressaltar aqui que a política defendida pelo Ministro é de afirmação de igualdade moral e civil, não de afirmação de diferenças para o estabelecimento de tratamento diferenciado. Britto efetua essa interpretação baseado em preceitos constitucionais e, sendo assim, ele parte de uma concepção de sociedade muito similar àquela desenhada por Rawls, qual seja, a da democracia constitucional composta por cidadãos livres e iguais que se respeitam reciprocamente:

Pluralismo [contido no inciso V do art. $1^{\circ}$ da Constituição de 1988] que serve de elemento conceitual da própria democracia material ou de substância, desde que se inclua no conceito da democracia dita substancialista a respeitosa convivência dos contrários. Respeitosa convivência dos contrários que John Rawls interpreta como a superação de relações historicamente 
servis ou de verticalidade sem causa. Daí conceber um "princípio de diferença" ${ }^{212}$, também estudado por Francesco Viola sob o conceito de "similitude". (BRASIL, 2011, p. 2083, grifo do autor)

Durante a construção de sua argumentação, Britto encontra-se com um fato que, em princípio, parece ser um obstáculo ao reconhecimento da união homoafetiva: a Constituição brasileira de 1988 não proíbe explicitamente o tratamento discriminatório baseado na orientação sexual. Contudo, o Ministro argumenta corretamente que, assim como a discriminação baseada no sexo (e em outros fatores biológicos) é proibida, tampouco se deve permitir tratamento discriminatório a uma pessoa em razão de seu comportamento sexual:

Preconceito é um conceito prévio. Uma formulação conceitual antecipada ou engendrada pela mente humana fechada em si mesma e por isso carente de apoio na realidade. Logo, juízo de valor não autorizado pela realidade, mas imposto a ela. [...] Há mais o que dizer desse emblemático inciso IV do art. $3^{\circ}$ da Lei Fundamental brasileira. É que, na sua categórica vedação ao preconceito, ele nivela o sexo à origem social e geográfica da pessoas [sic], à idade, à raça e à cor da pele de cada qual; isto é, o sexo a se constituir num dado empírico que nada tem a ver com o merecimento ou o desmerecimento inato das pessoas, pois não se é mais digno ou menos digno pelo fato de se ter nascido mulher, ou homem. [...]. Cuida-se, isto sim, de algo já alocado nas tramas do acaso ou das coisas que só dependem da química da própria Natureza, ao menos no presente estágio da Ciência e da Tecnologia humanas. (BRASIL, 2011, p. 2083-2084, grifo do autor)

É bastante perceptível que Britto reconhece que o sexo, a orientação sexual, a raça e outros fatores biológicos como "moralmente arbitrários"13, isto é, como fatores que independem da vontade do indivíduo, aos quais a pessoa se sujeita involuntariamente. Igualmente arbitrátio, desde um ponto de vista moral, é o preconceito, por ser imposto a uma realidade, a um grupo que com ele se vê obrigado a lidar. Por essa razão, autoridades públicas não poderiam priorizar um único tipo de sexo ou orientação sexual na definição de suas políticas públicas, mas devem tratá-los como igualmente merecedores de respeito. Da mesma forma, por ser uma questão estreitamente ligada à intimidade, ou privacidade individual, a Constituição de um Estado democrático jamais poderia pretender regulamentar como os cidadãos devem se portar em relação ao exercício de sua sexualidade, exceto "quando a sexualidade de uma pessoa é manejada para negar a sexualidade da outra, como sucede, por exemplo, com [...] o [...] estupro. Ou com o desvario ético-social da pedofilia e do incesto. Ou quando resvalar para a zona legalmente proibida do concubinato" (BRASIL, 2011, p. 2089). Infere-se desse trecho do voto de Britto que o Ministro corretamente interpreta que o exercício da sexualidade só pode ser regulamentado no que se refere à possibilidade de que tal exercício possa gerar danos a outros; interpretação bastante pertinente e condizente com um posicionamento liberal sobre a justiça, semelhante ao harm principle de Mill, "segundo o qual a coerção coletiva da sociedade só pode ser empregada para restringir a liberdade individual quando isso for necessário para evitar que danos sejam causados a outros" (VITA, 2009, p. 62). Portanto, o comportamento sexual configurar-seia numa liberdade constitucionalmente garantida sob o escopo do direito à intimidade e à privacidade:

Consignado que a nossa Constituição vedou às expressas o preconceito em razão do sexo e intencionalmente nem obrigou nem proibiu o concreto uso da sexualidade humana, o que se tem como resultado dessa conjugada técnica de normação éo

\footnotetext{
${ }^{12} \mathrm{O}$ texto de Britto não fornece elementos suficientes para dizer se a interpretação feita do princípio de diferença de Rawls está correta. Por isso, não me pronuncio sobre esse assunto.

${ }^{13}$ Para uma discussão sobre a aplicação do argumento da "arbitrariedade moral" ao fato do pluralismo razoável, ver VITA, 2009, p. 66-67.
} 
$\underline{\text { reconhecimento de que tal uso faz parte da autonomia de vontade das pessoas naturais, constituindo-se em direito subjetivo }}$ ou situação jurídica ativa. Direito potestativo que se perfila ao lado das clássicas liberdades individuais que se impõem ao respeito do Estado e da sociedade (liberdade de pensamento, de locomoção, de informação, de trabalho, de expressão artística, intelectual, científica e de comunicação, etc). (BRASIL, 2011, p. 2089-2090, grifo do autor)

Para o Ministro, a interpretação da instituição familiar como restrita apenas à família heterossexual seria resultante da discriminação ao comportamento homoafetivo e, portanto, desarrazoada, pois isso seria consagrar uma doutrina abrangente, ou a forma de vida heterossexual, como a única inteligível a toda uma sociedade. Em outras palavras, qualquer autoridade pública que atue dessa forma em suas decisões políticas agiria de forma intolerante em relação a todas as formas de família que não se enquadrem naquela definida pelos padrões heterossexuais. Assim, a forma razoável de se interpretar a instituição da família é concebê-la como um conceito aberto, modificável historicamente, devendo, portanto, ser contextualizado quando de sua aplicação:

A parte mais importante é a própria cabeça do art. 226 [da Constituição de 1988], alusiva à instituição da família, pois somente ela - insista-se na observação - é que foi contemplada com a referida cláusula da especial proteção estatal. Mas família em seu coloquial ou proverbial significado de núcleo doméstico, pouco importando se formal ou informalmente constituída, ou se integrada por casais heterossexuais ou por pessoas assumidamente homoafetivas. [...] nos quais permanece a invariável diretriz do não-atrelamento da formação da família a casais heteroafetivos nem a qualquer formalidade cartorária, celebração civil ou liturgia religiosa; vale dizer, em todos esses preceitos a Constituição limita o seu discurso ao reconhecimento da família como instituição privada que, voluntariamente constituída entre pessoas adultas, mantém com o Estado e a sociedade civil uma necessária relação tricotômica.

[...]

Em rigor, uma palavra-gênero, insuscetível de antecipado fechamento conceitual das espécies em que pode culturalmente se desdobrar. (BRASIL, 2011, p. 2095-2097, grifo do autor)

Britto reconhece que, como consequência de não se interpretar de forma fechada o conceito de família e de casais homo e heteroafetivos serem moralmente iguais e igualmente merecedores de respeito, a união homoafetiva deve ser reconhecida pelo Estado ${ }^{14}$ :

[...] a isonomia entre casais heteroafetivos e pares homoafetivos somente ganha plenitude de sentido se desembocar no igual direito subjetivo à formação de uma autonomizada família. Entendida esta, no âmbito das duas tipologias de sujeitos jurídicos, como um núcleo doméstico independente de qualquer outro e constituído, em regra, com as mesmas notas factuais da visibilidade, continuidade e durabilidade. Pena de se consagrar uma liberdade homoafetiva pela metade ou condenada a encontros tão ocasionais quanto clandestinos ou subterrâneos. Uma canhestra liberdade "mais ou menos", para lembrar um poema alegadamente psicografado pelo tão prestigiado médium brasileiro Chico Xavier, hoje falecido, que, iniciando pelos versos de que "A gente pode morar numa casa mais ou menos,/Numa rua mais ou menos, / Numa cidade mais ou menos" / E até ter um governo mais ou menos", assim conclui a sua lúcida mensagem: "O que a gente não pode mesmo,/ Nunca, de jeito nenhum,/ É amar mais ou menos,/ É sonhar mais ou menos,/ É ser amigo mais ou menos,/ (...) Senão a gente corre o risco de se tornar uma pessoa mais ou menos"15. (BRASIL, 2011, p. 2100-2101, grifo do autor)

Por todo o anterior, parece que, de fato, não há qualquer objeção razoável contra a faculdade/capacidade da homoafetividade e ao consequente reconhecimento da união homoafetiva. A título de exemplo, menciono a tentativa dos amici curiae Confederação Nacional dos Bispos do Brasil (CNBB) e a Associação Eduardo Banks (AEB), as quais apresentaram argumentação oral no sentido de rejeitar os pedidos da APDF 132 e da ADI 4277.

${ }^{14}$ E mais, sob os mesmos argumentos, Britto também reconhece aos homoafetivos as possibilidades de casamento e adoção (BRASIL, 2011, p. 2105-2107).

${ }^{15}$ Nesse último trecho destacado do voto do Ministro, chama a atenção o fato de ele ter utilizado, entre os vários argumentos, ensinamentos espíritas que, no entanto, desempenham papel meramente retórico, sem nenhuma função fundamental à argumentação e, por isso, não a prejudica. 
Enquanto a CNBB suscitou argumentos redundantes de que a união homoafetiva deve ser negada apenas porque a Constituição não a reconhece explicitamente, a AEB só apresentou objeções arraigadas preponderantemente e explicitamente - em razões religiosas, segundo as quais só haveria um único tipo de família, aquela formada por casais heterossexuais. Sendo assim, segundo a ideia de razão pública, se a união homoafetiva não foi razoavelmente rejeitada quando do debate público, não há razões para que ela não seja aceita. Ou, como muito bem colocado por Britto, sua decisão baseia-se numa ideia de "igualdade pura e simples, pois não se pode alegar que os heteroafetivos perdem se os homoafetivos ganham. E quanto à sociedade como um todo, sua estruturação é de se dar, já o dissemos, com fincas na fraternidade, no pluralismo e na proibição do preconceito" (BRASIL, 2011, p. 2106), segundo interpretação constitucional. A decisão tomada pelo STF brasileiro é, portanto, dotada de legitimidade, considerando-se os critérios da ideia de razão pública estabelecidos por Rawls.

\section{CONCLUSÃO}

Por meio deste texto, procurei apresentar a parte da teoria da justiça de Rawls pertinente ao que ele compreende por tolerância. Tentei fazê-lo de uma maneira que lhe fosse fiel. Para tanto, apoiado principalmente nas reflexões de Valentini sobre a forma adequada de se compreender uma teoria ideal como a de Rawls, apresentei, primeiramente, a idealização de pessoa por ele construída: um cidadão racional e razoável, membro de uma sociedade democrática, constitucional e bem-ordenada segundo princípios de justiça. Rawls reconhece nesse cidadão uma identidade política, constituída, em especial, pelas capacidades morais de se ter uma concepção de bem e um senso de justiça; pela disposição de propor e aceitar termos razoáveis e equitativos de cooperação social, bem como de reconhecer e respeitar os limites do juízo, que restringem o campo de aceitabilidade dos argumentos apresentados num debate público; e, como consequência das características anteriores, o cidadão age em relação ao outro de forma reciprocamente respeitosa. Ressaltei que esse ideal de cidadão não deve ser entendido como o sujeito a quem se destina a teoria de Rawls, mas apenas e estritamente como um aparato teórico mobilizado como suporte de sua ideia de razão pública, ideia sobre a qual se fundamenta o consenso sobreposto de doutrinas abrangentes e razoáveis; ideia que possibilita a estabilidade, a unidade social. Busquei demonstrar também como a razão pública foi concebida por Rawls não como mero teste de avaliação de argumentos, mas como a razão que deve orientar autoridades públicas no debate sobre questões políticas fundamentais, de forma a possibilitar um desenho institucional que não priorize nenhuma doutrina abrangente sobre as demais, mas que, orientada pelo respeito mútuo, permita o pleno desenvolvimento de todos os planos de vida razoáveis de cidadãos razoáveis; que se configure, portanto, numa estrutura social básica tolerante. Por fim, ao tomar o ideal de razão pública rawlsiano como guia da ação, propus uma avaliação dos argumentos utilizados pelo Ministro do STF Carlos Ayres Britto na ADPF 132 e na ADI 4277, ações constitucionais que tinham como 
objeto de questionamento a configuração da família definida constitucionalmente e, como pedido, o reconhecimento da união homoafetiva, uma concepção de família formada por homossexuais, ou homoafetivos, como se tem nomeado ultimamente. De fato, pude concluir que a decisão tomada pelo Ministro - e aprovada por unanimidade pelos demais Ministros presentes no plenário - de reconhecer esse tipo de união civil estável é perfeitamente condizente com a ideia de razão pública de Rawls, principalmente, por ter se baseado numa ideia de igualdade civil e moral entre todos os cidadãos brasileiros, sejam eles hetero ou homoafetivos; e, sendo assim, dotada de plena legitimidade.

\title{
JOHN RAWLS' IDEA OF PUBLIC REASON AND THE JURIDICAL RECOGNITION OF THE HOMOSEXUAL CIVIL UNION IN BRAZIL
}

\begin{abstract}
This article aims to evaluate, according to the criteria of John Rawls' idea of public reason, the legitimacy of the decision taken by the Brazilian Supreme Court on the recognition of the homosexual civil union. In order to do so, I use Rawls' idea of public reason and argue that it should be understood as an ideal to guide action in reality. Initially, as a support for his conception of public reason, I present the rawlsian ideal of person: a rational and reasonable citizen, who is endowed with the moral capacities of having a conception of the good and a sense of justice, who acts in a reciprocally respectful manner, and who is a member of a democratic, constitutional and well-ordered society according to principles of justice. I also demonstratehow the idea of public reason should guide public authorities in the debate on fundamental political issues in order to enable the establishment of a tolerant basic social structure. Finally, when applying the criteria of public reason to the decision of the Supreme Court, I conclude on its legitimacy.
\end{abstract}

Keywords: Liberalism; John Rawls; Tolerance; Public Reason; Homosexual Civil Union.

\section{REFERÊNCIAS BIBLIOGRÁFICAS}

BARRY, Brian. "John Rawls and the search for stability". Ethics, vol. 105, n. 4, p. 874-915, jul. 1995. Justice as impartiality. Oxford: Clarendon Press, 1995.

BRASIL. Código Civil, Lei $\mathrm{n}^{\circ} \mathbf{1 0 . 4 0 6}$, de 10 de janeiro de 2002. Disponível em: http://www.planalto.gov.br/ccivil_03/leis/2002/L10406.htm. Acesso em: 18 ago. 2015.

Supremo Tribunal Federā. Acórdão da Arguição de Descumprimento de Preceito Fundamental no 132.

Brasilia, DF, 04 e 05 de maio de 2011. Disponível em: <http://redir.stf.jus.br/paginadorpub/paginador.jsp?docTP=TP\&docID=1538698\#114\%20-

\%20AC\%D3RD\%C3O>. Acesso em: 18 ago. 2015.

FORST, Rainer. "Os limites da tolerância". Novos Estudos. São Paulo, n. 84, p. 15-29, 2009. Disponível em: $<$ http://www.scielo.br/scielo.php?pid=S0101-33002009000200002\&script=sci_arttext >. Acesso em: 18 ago. 2015. 
MICHELMAN, Frank I. "Rawls on constitutionalism and constitutional law". In: FREEMAN, Samuel (Org.). The Cambridge Companion to Rawls. Cambridge: Cambridge University Press, 2008, p. 394-425.

NAGEL, Thomas. "Rawls and liberalism”. In: FREEMAN, Samuel (Org.). The Cambridge Companion to Rawls. Cambridge: Cambridge University Press, 2003, p. 62-85.

RAWLS, John. O liberalismo político. Tradução Álvaro de Vita. São Paulo: WMF Martins Fontes, 2011. Uma teoria da justiça. Tradução Jussara Simões. São Paulo: Martins Fontes, 2008.

SCANLON, Thomas. The difficulty of tolerance. Cambridge: Cambridge University Press, 2003.

VALENTINI, Laura. "On the apparent paradox of ideal theory". The Journal of Political Philosophy, vol. 17, n 3 , p. 332-355, 2009 .

VITA, Álvaro de. "Sociedade democrática e tolerância liberal". Novos Estudos. São Paulo, n. 84, p. 61-81, 2009. Disponível em: <http://www.scielo.br/scielo.php?pid=\$0101-33002009000200005\&script=sci_arttext>. Acesso em: 18 ago. 2015.

A justiça igualitária e seus críticos. São Paulo: Martins Fontes, 2007.

Trabalho enviado em 18 de agosto de 2015.

Aceito em 18 de outubro de 2015. 